\title{
Profiling of Wheat Class III Peroxidase Genes Derived from Powdery Mildew-Attacked Epidermis Reveals Distinct Sequence-Associated Expression Patterns
}

\author{
Guosheng Liu,, Xiaoyan Sheng, ${ }^{1}$ David L. Greenshields, ${ }^{1}$ Adam Ogieglo,, Susan Kaminskyj, ${ }^{1}$ \\ Gopalan Selvaraj, ${ }^{2}$ and Yangdou Wei ${ }^{1}$ \\ ${ }^{1}$ Department of Biology, University of Saskatchewan, Saskatoon, S7N 5E2, Canada; ${ }^{2}$ National Research Council of Canada, \\ Plant Biotechnology Institute, Saskatoon, S7N 0W9, Canada
}

Submitted 23 December 2004. Accepted 23 February 2005.

A cDNA library was constructed from leaf epidermis of diploid wheat (Triticum monococcum) infected with the powdery mildew fungus (Blumeria graminis f. sp. tritici) and was screened for genes encoding peroxidases. From 2,500 expressed sequence tags (ESTs), 36 cDNAs representing 10 peroxidase genes (designated $T m P R X 1$ to $T m P R X 10$ ) were isolated and further characterized. Alignment of the deduced amino acid sequences and phylogenetic clustering with peroxidases from other plant species demonstrated that these peroxidases fall into four distinct groups. Differential expression and tissue-specific localization among the members were observed during the $B$. graminis f. sp. tritici attack using Northern blots and reverse-transcriptase polymerase chain reaction analyses. Consistent with its abundance in the EST collection, TmPRX1 expression showed the highest induction during pathogen attack and fluctuated in response to the fungal parasitic stages. TmPRXI to TmPRX6 were expressed predominantly in mesophyll cells, whereas $T m P R X 7$ to $T m P R X 10$, which feature a putative C-terminal propeptide, were detectable mainly in epidermal cells. Using TmPRX8 as a representative, we demonstrated that its $\mathrm{C}$-terminal propeptide was sufficient to target a green fluorescent protein fusion protein to the vacuoles in onion cells. Finally, differential expression profiles of the TmPRXs after abiotic stresses and signal molecule treatments were used to dissect the potential role of these peroxidases in multiple stress and defense pathways.

Additional keywords: cell wall appositions (CWAs), papilla, reactive oxygen species (ROS).

Peroxidases (PRXs) are members of a large group of hemecontaining glycoproteins that catalyze oxidoreduction between $\mathrm{H}_{2} \mathrm{O}_{2}$ and various reductants and exist in almost all living organisms (Hiraga et al. 2001; Welinder 1992). Unlike most other enzymes, PRXs may have roles in both the production

Corresponding author: Yangdou Wei; Telephone: (306) 966-4447; Fax: (306) 966-4461; E-mail: yangdou.wei@usask.ca

G. Liu and X. Sheng contributed equally to the work.

Nucleotide sequence data is available under the following accession numbers: TmPRX1, AY857755; TmPRX2, AY857756; TmPRX3, AY857757; TmPRX4, AY857758; TmPRX5, AY857759; TmPRX6, AY857760; TmPRX7, AY857761; TmPRX8, AY857762; TmPRX9, AY857763; TmPRX10, AY857764; and TmGPD1, AY857765. and scavenging of reactive oxygen species (ROS). Plant PRXs (EC 1.11.1.7), designated class III PRXs (Duroux and Welinder 2003; Welinder 1992), are members of a large gene family. For example, the recently sequenced genomes in the dicot Arabidopsis thaliana (ecotype Columbia) and the monocot rice (Oryza sativa subsp. japonica) contain 73 and 138 peroxidaselike genes, respectively (Passardi et al. 2004; Tognolli et al. 2002), and show diverse expression profiles (Hiraga et al. 2000; Park et al. 2003; Tognolli et al. 2002; Valério et al. 2004). The existence of a large group of isoforms suggests that the proteins encoded by these genes are involved in a broad spectrum of physiological processes, requiring abundant or redundant members to act efficiently during normal and stress conditions. The proposed functions of class III PRXs include lignification (Whetten et al. 1998), suberization (Espelie et al. 1986; Roberts and Kolattukudy 1989), cross-linking of cell wall structural proteins (Fry 1986), auxin catabolism (Lagrimini et al. 1997), defense against pathogen attack (Chittoor et al. 1999; Delannoy et al. 2003; Rasmussen et al. 1995), salt tolerance, oxidative stress protection (Amaya et al. 1999), cell elongation (Hiraga et al. 2001), and ROS generation (Blee et al. 2001; Bolwell et al. 2002; Bolwell and Wojtaszek, 1997; Mittler et al. 2004).

Plant PRX protein sequences are characterized by the presence of highly conserved amino acids, including two histidine residues interacting with the heme group and eight cysteine residues forming disulphide bridges (Welinder et al. 2002). A variable region might reflect diversified substrate specificities and biological function of individual PRXs (Gajhede et al. 1997; Longu et al. 2004). Other structures in the protein also might be important for the compartmentalization and function of the enzymes, although there is not much direct evidence to support this. For example, a short span of propeptide at N-terminus has been proposed to be necessary for sorting the protein through endoplasmic reticulum (ER) to the outside of plant cell, and a C-terminal extension (CTE) probably to be responsible for vacuolar targeting (Buffard et al. 1990; Johansson et al. 1992; Rasmussen et al. 1995).

One of the major stress stimuli that plants encounter is pathogen attack. Previous studies have indicated the involvement of PRXs in defense against pathogen infection in various plant species and, hence, the pathogen-inducible $P R X s$ have been categorized into the $P R-9$ family of pathogenesis-related $(P R)$ genes (van Loon and van Strien 1999). Few pathogen-inducible $P R X$ genes have been reported, such as poxwht and pox 2 in wheat (Triticum aestivum L.) that respond to Blumeria graminis f. sp. tritici infection (Baga et al. 1995; Rebmann et al. 1991), 
POX22.3 and POX8.1 in rice that respond to Xanthomonas oryzae pv. oryzae (Chittoor et al. 1997), and Prx7 and Prx8 in barley (Hordeum vulgare L.) that respond to B. graminis f. sp. hordei (Kristensen et al. 1999). However, the information regarding systemic investigation of $P R X s$ in a specific pathosystem is still limited. In spite of their role in $\mathrm{H}_{2} \mathrm{O}_{2}$-dependent cell wall modifications, some PRXs also may be responsible for the production of $\mathrm{H}_{2} \mathrm{O}_{2}$ (Blee et al. 2001; Bolwell et al. 2002; Bolwell and Wojtaszek 1997). The $\mathrm{H}_{2} \mathrm{O}_{2}$ produced by these PRXs might serve as the substrate for other PRXs, or act as antimicrobial agents and signals to trigger self-defense responses like the hypersensitive response (HR) or production of phytoalexins (Wojtaszek 1997).

Pathogen-inducible $P R X$ genes also can be induced by different defense-related signal molecules and environmental stresses (Curtis et al. 1997; Hiraga et al. 2001; Ito et al. 1994). For example, abiotic stresses such as UV light, osmotic stress, high or low temperature, and mechanical damage also regulate $P R X$ gene expression in similar or overlapping patterns with pathogen attack and signaling molecule treatments, indicating that PRXs are involved in the complex networks for fine-tuning the stress response in plants (Cheong et al. 2002; Chini et al. 2004; Pastori and Foyer 2002).

Although some PRXs have been investigated rigorously, especially horseradish (Armoracia rusticana) peroxidase C (HRPC), many important aspects, such as tissue-specific or subcellular localizations of the proteins, coordinate and differential regulation of individual PRXs toward single or multiple stresses remain unknown. Given the sporadic and varied reports concerning PRX gene expression during defense and stress responses, elucidation of gene expression profiles at a genomic level in a specific plant-pathogen system appears to be justified. In order to identify a full set of pathogen-induced $P R X$ genes and their potential functions, we established a cDNA library from B. graminis f. sp. tritici-infected diploid wheat ( $T$. monococcum) epidermis, isolated all candidate $P R X$ genes, and investigated their expression patterns in response to pathogen attack, signal molecule treatments, and abiotic stresses, as well as tissue-specific and subcellular localization. This will provide a basis for our understanding of the function of $P R X s$ during the wheat $-B$. graminis $\mathrm{f}$. sp. tritici interaction.

\section{RESULTS}

Ten different $T m P R X$ genes isolated from pathogenattacked epidermis library.

An epidermal cDNA library from $T$. monococcum leaves at 24 to $48 \mathrm{~h}$ after powdery mildew infection served as a source of various $P R X$ genes responding to the infection. Among the 2,500 expressed sequence tags (ESTs), amino acid sequences deduced from 36 cDNA clones showed high similarity to typical class III plant PRXs, which invariably contain two histidines and eight cysteine residues and other conserved domains (excluding two partial sequences) (Table 1; Fig. 1). These TmPRXs account for approximately $1.5 \%$ of total ESTs, representing the largest class of genes expressed in T. monococcum leaf epidermis inoculated with $B$. graminis f. sp. tritici. Further analysis on sequence similarities showed that the 36 clones represented 10 different TmPRX genes, which were designated $T m P R X 1$ to TmPRX10. One representative clone for each gene was chosen for further molecular characterization. It is noteworthy that TmPRXI was the most frequently detected gene, represented by 15 clones, followed by $T m P R X 3, T m P R X 4$, and $T m P R X 2$, represented by 10,3 , and 2 clones, respectively, whereas the remaining six genes were only found once in the library (Table 1).

The identities among the $10 \mathrm{TmPRX}$-deduced amino acid sequences range from 36.0 to $95.8 \%$ (data not shown), although TmPRX5 and TmPRX9 were only partial sequences. Comparative analysis of the deduced amino acid sequences of the genes revealed that they contain conserved structural features and activity sites of typical class III PRXs (Fig. 1A), such as predicted ER-targeting N-terminal propeptides (NTPP), eight cysteine residues involved in the formation of four disulfide bridges, catalytic center distal heme-binding domain (Hd) and proximal heme-binding domain ( $\mathrm{Hp}), \mathrm{N}$-glycosylated triplets, and a variable region 40 to 50 amino acids (aa) toward the carboxyl end of the proximal heme-binding site (Gajhede et al. 1997). Chittoor and associates (1999) suggested that these variable sequences correlate with the substrate specificity of the protein.

Based on isoelectronic point $(\mathrm{pI})$ predictions (Table 1), mature proteins represent either basic (TmPRX3 and TmPRX6) or acidic (TmPRX1, 2, 4, 7, 8, and 10) isoforms of PRX, with pIs ranging from 5.52 to 8.44 . Although all of the full-length predicted TmPRX proproteins contain the NTPP, TmPRX7 to 10 also carry a distinct CTE (Fig. 1A).

TmPRXI had the highest putative identity to TAPERO (CAA39486, 96\%), a B. graminis f. sp. tritici-inducible $P R X$ gene isolated from bread wheat ( $T$. aestivum L.) leaves (Rebmann et al. 1991). The second most frequently detected clone, TmPRX3, showed very high identity to pox2 (CAA59485, $99 \%$ ), another $P R X$ gene induced by $B$. graminis f. sp. tritici in bread wheat (Baga et al. 1995). Other PRX orthologs (over $74 \%$ identity) from different monocot plants (rice and barley) can be identified for the rest of TmPRXs (Table 1).

To assess relationships within this group of genes and with plant PRXs from other sources, we compared each TmPRX against the whole family of PRXs in rice and Arabidopsis genomes. The phylogenetic tree generated by encompassing

Table 1. List of expressed sequence tags isolated from Blumeria graminis f. sp. tritici-infected wheat epidermis cDNA library

\begin{tabular}{|c|c|c|c|c|c|}
\hline Gene name & GenBank accession no. ${ }^{a}$ & Copy & $\mathbf{A A}$ & $\mathbf{p I}^{\mathbf{b}}$ & Closest ortholog (identity \%), reference ${ }^{\mathrm{c}}$ \\
\hline TmPRX1 & AY857755 & 15 & 312 & 5.52 & Triticum aestivum PERO (96), Rebmann et al. 1991 \\
\hline $\operatorname{TmPRX} 2$ & AY857756 & 2 & 316 & 5.79 & Hordeum vulgare PEROX1 (94), Thordal-C. et al. 1992 \\
\hline $\operatorname{TmPRX} 3$ & AY857757 & 10 & 314 & 8.44 & T. aestivum pox2 (99), Baga et al. 1995 \\
\hline $\operatorname{TmPRX} 4$ & AY857758 & 3 & 313 & 5.79 & Orzya sativa $\mathrm{POX} 8.1$ (77), Chittoor et al. 1997 \\
\hline $\operatorname{TmPRX} 5$ & AY857759 & 1 & $236^{\mathrm{d}}$ & $\ldots$ & O. sativa POX8.1 (77), Chittoor et al. 1997 \\
\hline $\operatorname{TmPRX6}$ & AY857760 & 1 & 322 & 8.42 & O. sativa OsPrx30 (75), Passardi et al. 2004 \\
\hline $\operatorname{TmPRX7}$ & AY857761 & 1 & 343 & 5.52 & O. sativa OsPrx39 (84), Passardi et al. 2004 \\
\hline $\operatorname{TmPRX8}$ & AY 857762 & 1 & 356 & 5.97 & O. sativa OsPrx72 (74), Passardi et al. 2004 \\
\hline $\operatorname{TmPRX9}$ & AY 857763 & 1 & $109^{d}$ & $\ldots$ & H. vulgare Prx7 (80), Kristensen et al. 1999 \\
\hline $\operatorname{TmPRX10}$ & AY857764 & 1 & 342 & 5.62 & H. vulgare Prx7 (76), Kristensen et al. 1999 \\
\hline
\end{tabular}

${ }^{a}$ mRNAs isolated from epidermis library of T. monococcum line 441.

${ }^{\mathrm{b}}$ Isoelectronic point (pI) for mature protein was estimated by Swiss-Prot/TrEMBL.

${ }^{\mathrm{c}}$ Closest orthologous protein accession number and percent identify were obtained by BLASTing NCBI server.

${ }^{\mathrm{d}}$ Partial sequences. 
20 rice PRXs and 13 Arabidopsis PRXs is shown in Figure 1B. The 20 selected PRXs in rice represent one to five members from each of eight clusters, except for OsPrx73, which is used as the tree root (Passardi et al. 2004). The 13 Arabidopsis PRXs represent the members in five distinct groups (Tognolli et al. 2002; Valério et al. 2004). In the phylogenetic tree, the 10 TmPRX proteins fall in four discrete clusters: six members in cluster 1 (TmPRX1 to TmPRX6), one member in clusters 2 (TmPRX7) and 3 (TmPRX8), and two members in cluster 4 (TmPRX9 and TmPRX10). The last three clusters were considerably divergent, suggesting more ancient differentiation. The other feature indicating that these three clusters are different from cluster 1 is that they possess a distinguishing structural feature, the CTE (Fig. 1A), which has been speculated to be a vacuolar sorting signal. As expected, Figure 1B shows that TmPRXs are more closely related to the monocot rice than the dicot Arabidopsis. Further analysis reveals that clusters 1 to 4 of TmPRXs fall in the groups IV, III, I, and II of OsPrxs (Passardi et al. 2004), respectively. None of the TmPOXs are closely related to OsPrx groups V to VIII. Interestingly, two members from rice peroxidase group IV, OsPrx110 and OsPrx111, which are grouped into TmPOX cluster 1, are equivalent to pathogen-inducible POX8.1 and POX22.3, respectively (Chittoor et al. 1997), implying the possible involvement of group IV OsPrxs in plant-pathogen interactions. Most of the TmPRXs are not grouped closely with Arabidopsis PRXs, except for TmPRX7, which is similar to Arabidopsis AtPrx17 (AT2G22420, 70.0\% identity at putative protein level).

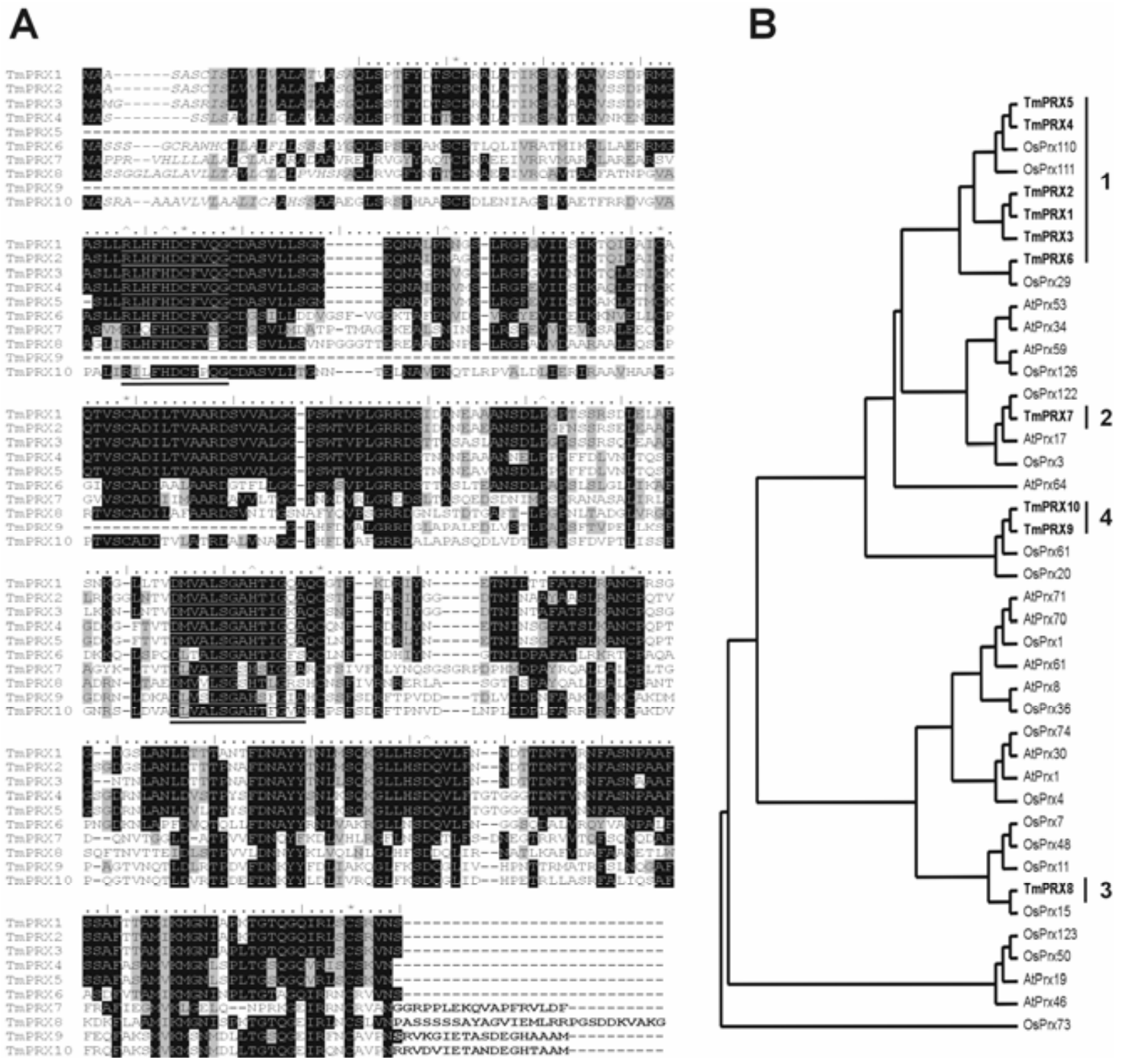

Fig. 1. Alignment of predicted amino acid sequences of TmPRX genes and their phylogenetic relationship to representative rice and Arabidopsis peroxidases. A, ClustalW alignment of 10 TmPRXs. Residues that are conserved in at least five of the sequences are highlighted black and residues that are similar are highlighted gray. Dashes represent spaces introduced to maximize alignment. Putative N-terminal signal motifs (NTPP) are italicized and C-terminal extensions (CTE) are bolded. Two heme-binding domains (Hd: residues 38 to 48; Hp: residues162 to 175) are underlined. The eight conserved cysteine residues expected to form four disulphide bridges are marked with * and putative active sites (such as N-glycosylated triplets) were labeled with ${ }^{\wedge}$ on the top of sequences. The motifs and active site predictions were performed with SIGNALP or NetNGlyc. B, Phylogenetic relationships between Triticum monococcum and representative rice (Passardi et al. 2004) or Arabidopsis (Tognolli et al. 2002; Valério et al. 2004) peroxidases. The tree is rooted by a putative ancestral rice peroxidase OsPrx73 and represents the consensus of 100 possible trees made with the PROTDIST and NEIGHBOR methods using the Phylip phylogeny package. The TmPRX are bolded and groups 1 to 4 are indicated to the right. 
Expression of $\operatorname{TmPRX}$ genes is induced by $B$. graminis f. sp. tritici attack.

To evaluate the transcriptional expression of $T m P R X$ genes during the process of wheat $-B$. graminis $\mathrm{f}$. sp. tritici interacttion, six genes, three from cluster 1 (TmPRX1, TmPRX4, and TmPRX6) and one from each of the other three clusters (TmPRX7, TmPRX8, and TmPRX10), were chosen and monitored at the transcript level over a $144-\mathrm{h}$ period on susceptible line 441 and resistant line 453 by Northern blot analyses (Fig. 2).

As in the EST frequencies in the library, TmPRX1 transcripts in susceptible line 441 were the highest during pathogen attack. In addition, $T m P R X 1, T m P R X 4$, and TmPRX6 all show a similar pattern of expression in response to infection, despite differing transcriptional intensities. TmPRX1 mRNA was induced at $3 \mathrm{~h}$ postinoculation (hpi) and then increased at $6 \mathrm{hpi}$, followed by a slight decrease in transcript level at 12 hpi and then a sharp increase at $24 \mathrm{hpi}$. The matching time points for $B$. graminis $\mathrm{f}$. sp. tritici infection at 3 to 6 and 12 to 24 hpi are the attempted penetration of the primary germ tube (pgt) and the appressorial germ tube (agt), respectively, indicating the involvement of TmPRXs during the infection process. The signal reaches a third peak at 120 to $144 \mathrm{hpi}$, in accordance with abundant secondary hypha penetration.

The expression of TmPRX1 in resistant line 453 is also notably higher than any other TmPRX genes, and TmPRX4 and TmPRX6 show similar but weaker patterns of induction. The difference between TmPRXI expressions in the two lines is that the signal disappears after 72 hpi in line 453, suggesting that the gene expressions are coordinated with the fungal penetration and proliferation. In the susceptible host, a large percentage of appressoria led to successful penetration of the host cell wall and produced haustoria in the epidermal cells between 24 and 48 hpi. Penetration by secondary hyphae began after 72 hpi. Subsequently, colonies formed and sporulation began, and secondary cycles of penetration elicited the continuous responses for the $\operatorname{TmPRX}$ genes. In the resistant line, however, successful blocking of fungal appressorium-mediated penetration was not followed by further defense gene expression during the time course.

The expression patterns of $T m P R X 8$ and TmPRX10 were similar in both compatible and incompatible lines, with maximal transcription at $24 \mathrm{hpi}$. In contrast to the transient induction of cluster $1 \mathrm{TmPRXs}$ in the resistant line 453, TmPRX8 expression remained high throughout the later part of the time course. No visible transcript accumulation was detected in this time course for TmPRX7, suggesting that it might not be directly involved in the defense response to $B$. graminis f. sp. tritici, or that the transcription is downregulated after pathogen attack (Fig. 3).

\section{Differential expression profiling of TmPRX genes in epidermal and mesophyll cells reveals distinct tissue-specific localization.}

The epidermis provides the major line of defense against infection by the surface-growing powdery mildew fungus. To further investigate whether the expression patterns of the $T m P R X$ s differ between epidermis and other cell types, samples from susceptible line 441 epidermis and mesophyll tissues were collected at 0,24 , and $48 \mathrm{hpi}$. Gene-specific primers (most of them generated from flanking $5^{\prime}$ or $3^{\prime}$ untranslated regions) for each $T m P R X$ were designed for reverse-transcriptase polymerase chain reaction (RT-PCR) to avoid nonspecific amplification (Table 2). Intriguingly, two major distinct expression patterns were found in the RT-PCR analysis (Fig. 3): $T m P R X$ genes from cluster 1 (TmPRX1 to TmPRX6) were expressed more highly in mesophyll cells than in epidermal cells, and, with the exception of TmPRX6, were induced after patho-
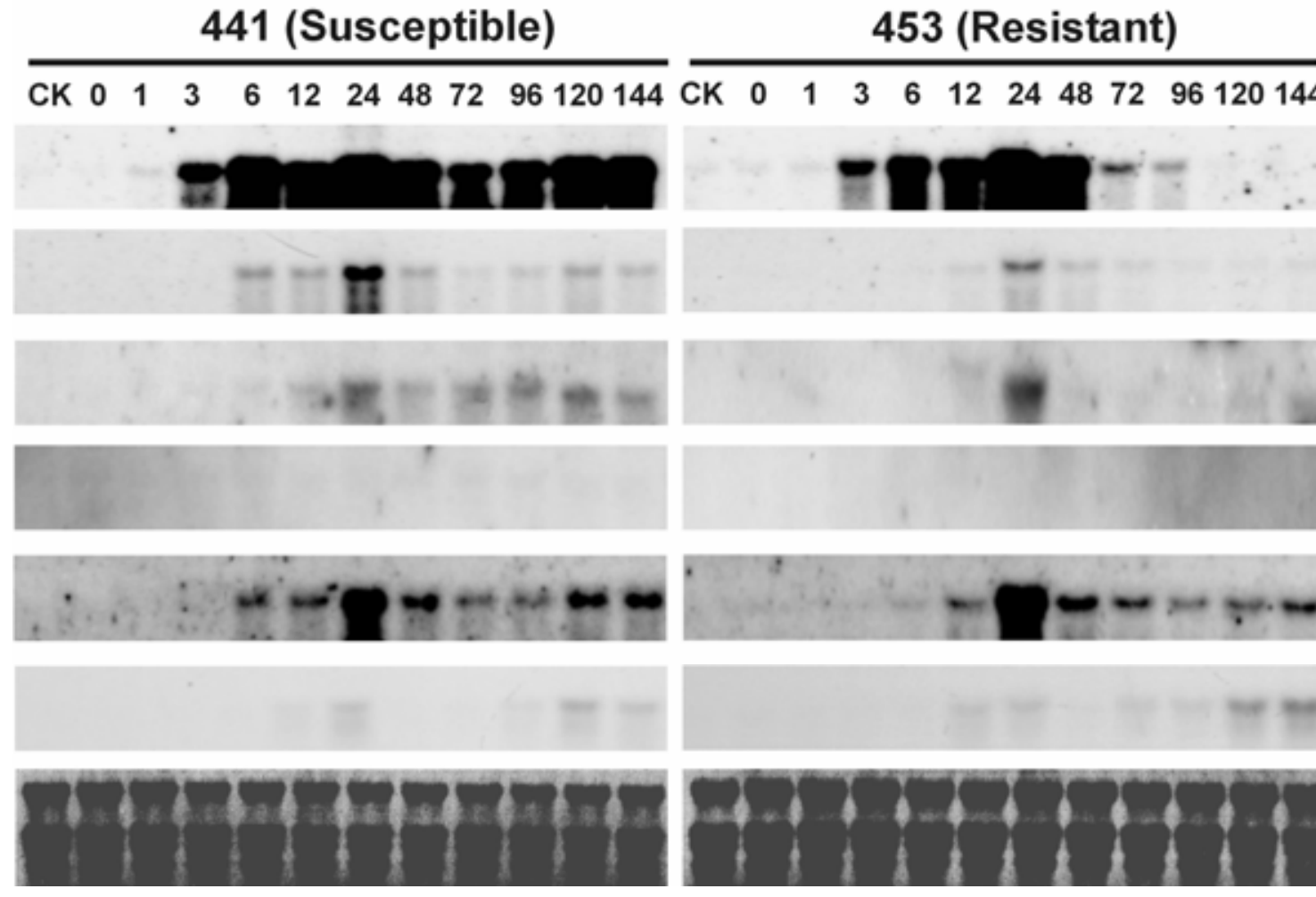

\section{hpi}

TmPRX1

TmPRX4

TmPRX6

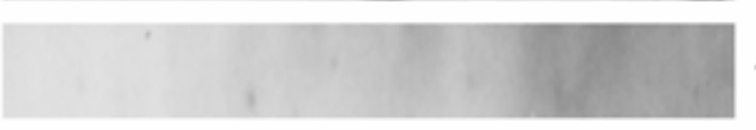

$\operatorname{TmPRX7}$

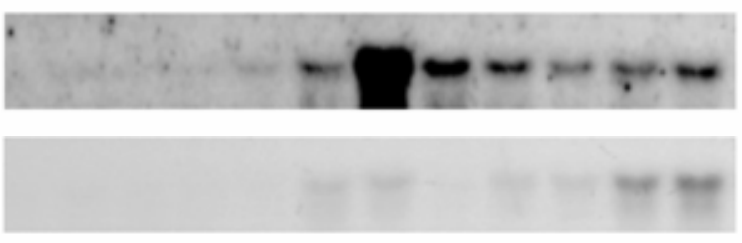

TmPRX8

TmPRX10

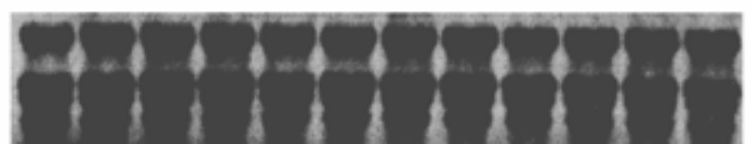

rRNA

Fig. 2. RNA gel blot analysis of 6 TmPRX genes in response to Blumeria graminis f. sp. tritici infection. Total RNA was isolated at 0 to $144 \mathrm{~h}$ postinoculation from the 10-day-old primary leaves inoculated with B. graminis f. sp. tritici conidia. Uninoculated leaves were used as controls (CK). Transcript levels of peroxidase genes were analyzed with ${ }^{32} \mathrm{P}$-labeled cDNA probes for TmPRX1, TmPRX4, TmPRX6, TmPRX7, TmPRX8, and TmPRX10. Total RNA was loaded at $20 \mu \mathrm{g}$ per lane and equal loading was monitored by methylene blue staining of ribosomal RNA. 
gen attack; whereas $T m P R X$ genes that fall into the other two clusters (e.g., $T m P R X 8, T m P R X 9$, and $T m P R X 10$ ) were expressed more predominantly in epidermal cells than in mesophyll cells both before and after pathogen attack, although the later expression was more pronounced. TmPRX7 appeared to be unique according to its insensitivity to pathogen attack even though weak expression could be detected in mesophyll cells of uninoculated leaves. Consistent with the Northern blot analysis (Fig. 2, where tissue-specific expressions are not distinguished), RT-PCR demonstrated the high expression after pathogen attack and maximal expression intensity at $24 \mathrm{hpi}$. Except for TmPRX6 in cluster 1 (which was dissimilar to the other five members) (Fig. 1B), basal expression of TmPRXs
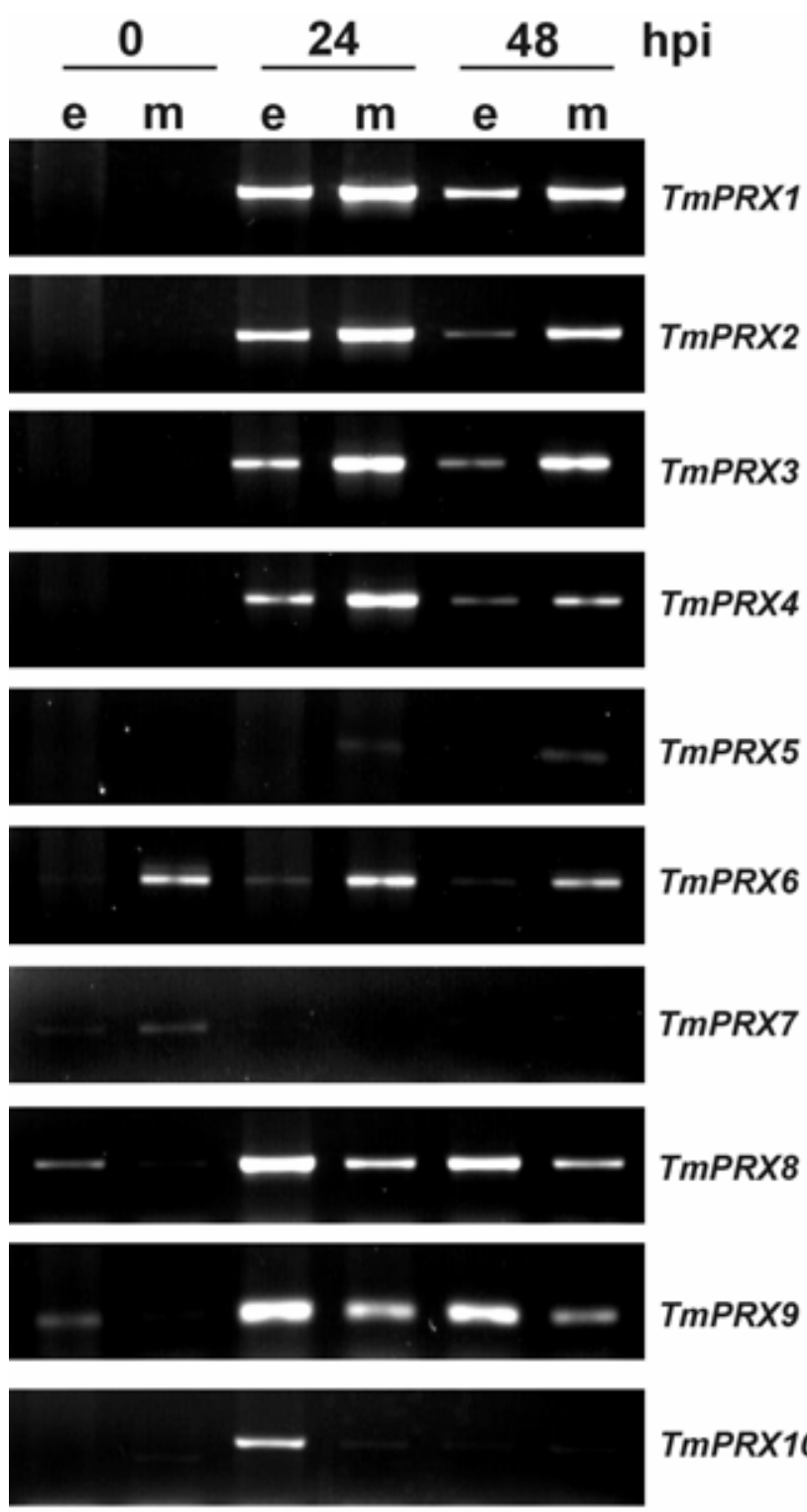

$\operatorname{TmPRX10}$

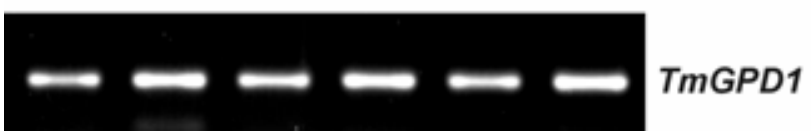

Fig. 3. Reverse-transcriptase polymerase chain reaction analysis of tissuespecific expressions of 10 TmPRX genes in response to Blumeria graminis f. sp. tritici attack. Total RNAs were isolated from epidermal (e) and mesophyll (m) tissues 0,24 , and $48 \mathrm{~h}$ postinoculation on line 441 and reverse transcribed to cDNA. The expression of a glyceraldehyde-3-phosphate dehydrogenase 1 gene (TmGPD1) was used as a control of mRNA normalization. (before $B$. graminis f. sp. tritici attack; i.e., at 0 hpi) were observed in clusters 2,3 , and 4 . It is worthy to note that, although all the plant peroxidases possessed a signal peptide for secretion, all cluster 1 TmPRXs bore only the NTPP, and other three cluster-related TmPRXs had both the NTPP and CTE, suggesting that the sequence-related localization of $T m P R X$ expression was evident in the epidermis and mesophyll layers of leaves inoculated with $B$. graminis f. sp. tritici.

Expression of $T m P R X$ genes in response to abiotic stresses.

Substantial interactions or cross-talking in plants among biotic or abiotic stress pathways have been reported (Cheong et al. 2002; Desikan et al. 2001; Llorente et al. 2002). Considering that PRX has multiple roles to stress responses (especially to the regulation of $\mathrm{H}_{2} \mathrm{O}_{2}$ ), it appears valuable to test whether the TmPRXs isolated from pathogen-induced ESTs also were regulated by abiotic stresses. The transcriptional changes of the same set of genes probed during pathogen challenge were investigated under stresses of salt, cold, dehydration, and wounding (Fig. 4). The TmPRXs showed differential reactions to the stresses; however, in general, it seems that salinity was the strongest $T m P R X$ inducer among the four treatments. Most of the $P R X$ s tested were induced by high concentration of salt $(200 \mu \mathrm{M} \mathrm{NaCl})$ after $6 \mathrm{~h}$ of treatment, with TmPRX1 showing the highest expression level. It is interesting to note that $T m P R X 7$ expression was strongly induced only by salt (compare Figs. 2, 3, and 5). The significance of the induction of TmPRXs by salt and mechanisms underlining the correlation between defense and salt tolerance remain to be clarified further. Compared with salt stress, cold and wounding did not significantly induce gene expression of the TmPRXs, and dehydration induced the expression of $T m P R X 8$ and marginal expression of TmPRX1 and TmPRX4.

\section{Expression of TmPRX genes}

in response to signaling molecules.

Plant-defense responses are mediated by highly regulated and coordinated signaling networks that rely on small molecules such as salicylic acid (SA), methyl jasmonate (MeJA), ethylene (ET), nitric oxide (NO), and $\mathrm{H}_{2} \mathrm{O}_{2}$ as secondary messengers to fine-tune responses (Dong 2001; Feys and Parker 2000; Hammond-Kosack and Parker 2003; Neill et al. 2002). To investigate which pathway or signal molecule might be involved in the regulation of TmPRX gene expression, we treated wheat plants with SA, MeJA, ethephon (ET releaser), sodium nitroferricyanide dehydrate (NO releaser), abscisic acid (ABA), and $\mathrm{H}_{2} \mathrm{O}_{2}$ and investigated the expression of the $T m P R X \mathrm{~s}$ in a time course (Fig. 5). Not surprisingly, the TmPRX genes showed varying expression patterns after treatments, indicating that the peroxidases were regulated differentially. TmPRX1 appeared to be upregulated by most of the signaling compounds assayed. TmPRX4 and TmPRX7 apparently were not responsive to the treatments, although TmPRX4 showed slight induction in response to MeJA. In general, MeJA, ET, NO, and $\mathrm{H}_{2} \mathrm{O}_{2}$ demonstrated a higher ability to induce expression, with MeJA having the strongest induction effect on all the TmPRXs except for TmPRX7 and TmPRX8. Highest inductions by MeJA were observed for TmPRXI and TmPRX10 at 6 to $24 \mathrm{~h}$ after treatment, indicating that the JA signaling pathway probably participated in regulation of the pathogen-induced $P R X$ expression. In contrast to MeJA, SA, an important signaling molecule in acidic $P R$ gene expression in dicot plants, had little effect on the gene expression of TmPRXs. It also was interesting that $\mathrm{H}_{2} \mathrm{O}_{2}$, both a critical signal molecule in defense responses and substrate of PRX, did not show the expected rapid induction of $T m P R X \mathrm{~s}$ except for $T m P R X 1$, and delayed induction of TmPRX8. 
A C-terminal propeptide is responsible for vacuolar localization of TmPRX8.

Two signal propeptides, NTPP and CTE, have been proposed to be responsible for the secretion of PRX to the apoplast or vacuole, respectively; however, little direct evidence was available to support this. In the present study, we found that four proproteins (TmPRX7 to 10) harbor the CTE. Given the divergent sequence and expression characteristics of TmPRX genes that include a CTE, we were interested to see whether this putative signal indeed represented a vacuolar targeting sequence, as had been suggested previously (Buffard et al. 1990; Johansson et al. 1992; Kristensen et al. 1999). To investigate the subcellular localization of CTE-containing TmPRXs, we chose one representative gene for green fluorescent protein (GFP) tagging from cluster 3, TmPRX8, which was expressed strongly following pathogen, abiotic, and signal molecule stresses. The 29-aa CTE coding sequence was fused to the carboxyl end of enhanced GFP in the plant expression vector pEGAD. Following particle bombardment of onion (Allium сера) epidermal strips with the resulting plasmid (pEGAD2135CTE), transient expression of the GFP fluorescence in both small and large vacuoles of onion cells was observed (Fig. 6). In contrast, the GFP fluorescence from the control vector was localized to the cytosol and nuclear matrix, and no detectable GFP accumulation was observed in the vacuoles, indicating that the 29-aa CTE of TmPRX8 governed vacuolar targeting and was highly specific. To our knowledge, this is first in planta evidence to confirm the vacuolar localization of PRXs driven solely by CTE signal peptide. Because there is very low sequence similarity among the TmPRX CTEs, whether the other three CTEs also possess similar function still remains to be clarified further.

Table 2. List of primers used for reverse-transcriptase polymerase chain reaction

\begin{tabular}{|c|c|c|c|}
\hline Primer name & Oligo sequences $\left(5^{\prime}-3^{\prime}\right)$ & Amplified gene & Product (bp) \\
\hline $1189 \mathrm{~F}$ & CCAGTAAAGAAGTGCAGGCAA & $\operatorname{TmPRX1}$ & 1,014 \\
\hline $1189 \mathrm{R}$ & TTGCGAGCGCAGCCGACT & & \\
\hline $1102 \mathrm{~F}$ & TGCAGGTAGCACGCATAGCTC & $T m P R X 2$ & 1,071 \\
\hline $1102 \mathrm{R}$ & TGCTGGTATGATAAGTGGTAT & & \\
\hline $962 \mathrm{~F}$ & TGGCTTTGCTCTTCA GCTCTT & $T m P R X 3$ & 1,023 \\
\hline $962 \mathrm{R}$ & GTGCTGACTAGTAGACAGTAA & & \\
\hline $\mathrm{BF} 1 \mathrm{~F}$ & ССТАТСАCAAАTCACAATTA & TmPRX4 & 1,106 \\
\hline BF1R & CATTGACATACGTATATGACA & & \\
\hline $2930 \mathrm{~F}$ & TGGCGAACTCTGACCT & TmPRX5 & 515 \\
\hline 2930R & ACCCATTTTTAGCAAT & & \\
\hline $620 \mathrm{~F}$ & GTAGCTAGATAGATTTGTGAG & TmPRX6 & 1,113 \\
\hline $620 \mathrm{R}$ & TCGAACCAAACGGCTCTTATT & & \\
\hline $399 \mathrm{~F}$ & CCGCGCGCCAACGCGAGCGC & $\operatorname{TmPRX7}$ & 629 \\
\hline 399R & AGAACTGCGACACGACCAAAC & & \\
\hline $2135 \mathrm{~F}$ & CCGACACCGGCGCGTTCACC & $\operatorname{TmPRX} 8$ & 663 \\
\hline $2135 \mathrm{R}$ & GTCTAGTATACGTGCGAACGG & & \\
\hline $414 \mathrm{~F}$ & AGCGTTGGAGGATCTCGTCTC & $\operatorname{TmPRX} 9$ & 388 \\
\hline $414 \mathrm{R}$ & CGTCGCCATGCGCGTGGTGTT & & \\
\hline $\mathrm{S} 15 \mathrm{~F}$ & CGGCCGCCGCGACGCGCTCG & TmPRX10 & 749 \\
\hline S15R & ATATACTCCTACTCTTGGTCT & & \\
\hline GPDH1F & GGCTCCGATCAAGATCGGCATC & TmGPD1 & 480 \\
\hline GPDH1R & GGAGCAAGGCAGTTAGTGGTGC & & \\
\hline
\end{tabular}

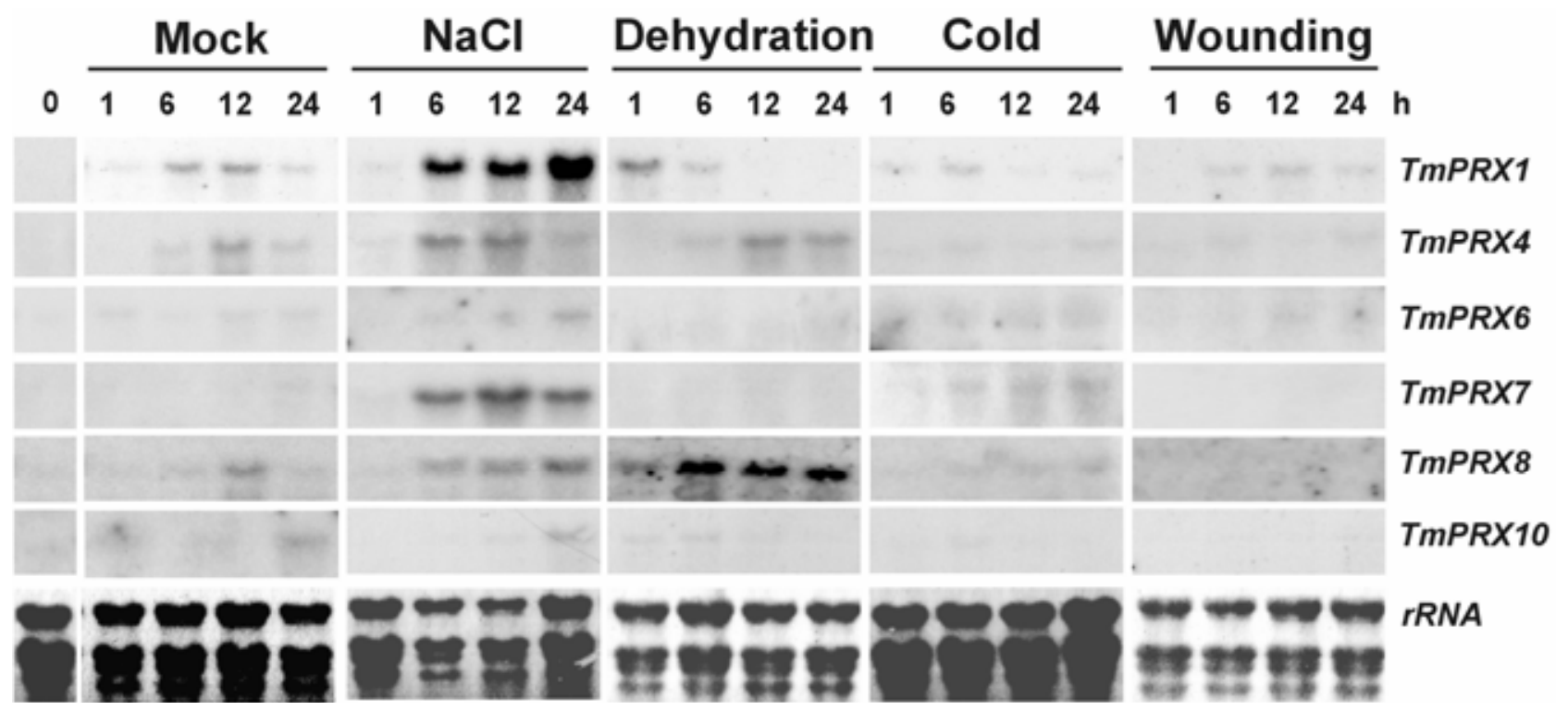

Fig. 4. RNA gel blot analysis of six TmPRX genes in response to abiotic stresses. Total RNA was isolated at 1, 6, 12, and $24 \mathrm{~h}$ posttreatment from10-day-old Triticum monococcum primary leaves subjected to $\mathrm{NaCl}$, cold, dehydration, and wounding. Mock-treated plants or leaves (mock) were used as controls. Transcript levels of $P R X$ genes were analyzed with ${ }^{32}$ P-labeled cDNA probes for TmPRX1, TmPRX4, TmPRX6, TmPRX7, TmPRX8, and TmPRX10. Total RNA was loaded at $20 \mu \mathrm{g}$ per lane and equal loading was monitored by methylene blue staining of ribosomal RNA. 


\section{DISCUSSION}

$P R X$ s form a large multigene family in plants. It has been estimated that 73 and 138 isoforms exist in Arabidopsis and rice, respectively (Passardi et al. 2004; Tognolli et al. 2002), and characterizing the function of each member or group of coordinated members remains challenging. EST libraries generated from specific conditions are no doubt a valuable tool for analyzing the involvement of multigene families at a genomic level. In this study, we investigated the regulation of individual $T m P R X$ genes in wheat in response to $B$. graminis $\mathrm{f}$. sp. tritici infection using a cDNA library established from diploid wheat leaf epidermis 24 to $48 \mathrm{~h}$ after $B$. graminis f. sp. tritici inoculation. This wheat $-B$. graminis f. sp. tritici pathosystem had several advantages for our objective. First, the diploid wheat (rather than common hexaploid wheat) had a simple AA genome (one of three sets of ancient chromosomes composing common wheat genome AABBDD), recognizable and reliable defense responses, and minimal redundant gene expression. Second, B. graminis f. sp. tritici only infects the epidermal cells, and host plant resistance depends largely on enhanced cell wall appositions (CWAs) or papilla, a localized strengthening of the cell wall in response to pathogen attack (Greenshields et al. 2004; Zeyen et al. 2002). Thus, a library constructed from this tissue provides a unique snapshot of host defense expression with minimal background noise.

Screening our epidermis library revealed 10 expressed TmPRX genes, represented by 36 ESTs. Based on the deduced protein structures, the 10 genes formed four clusters, where TmPRX1 to TmPRX6, TmPRX9 and TmPRX10, TmPRX7, and $T m P R X 8$ clustered into distinct groups. In general, the expression peaks of the TmPRX genes after pathogen attack were concomitant with pgt penetration at 3 to $6 \mathrm{hpi}$ and agt penetration at 12 to $24 \mathrm{hpi}$, although there was significant variation among individual genes. The largest transcript induction was found for the TmPRX1 gene in both compatible and incompatible lines, which is consistent with the findings that two powdery mildew-inducible PRX isozymes in barley, P8.5 and P5.2 (so-named because of their pI properties), specifically increased in both resistant and susceptible barley following inoculation with B. graminis f. sp. hordei, and P8.5 deposition was observed in CWAs (Scott-Craig et al. 1995). Induction of mRNA of TmPRX1 was observed within $3 \mathrm{hpi}$, implying that signals released by either spores or germlings on leaf surface were perceived by the host, although the nature of these putative signals is currently unknown. Interestingly, a recent study showed that inaccessibility to $B$. graminis f. sp. hordei could be induced in barley coleoptiles by extracellular material secreted by Erysiphe pisi or B. graminis f. sp. tritici (Fujita et al. 2004), suggesting that this extracellular material may be a signal for early gene induction. The obvious correlation between the expression pattern of $P R X$ genes and pathogenesis suggests that the $T m P R X$ s play important roles during the wheat $-B$. graminis $\mathrm{f}$. sp. tritici interaction. However, whether these pathogenesis-related $\operatorname{TmPRX}$ genes are responsible for resistance or susceptibility remains to be verified further. In some cases, highly induced $P R X$ genes in response to pathogen infection seemingly are related to disease resistance, such as two bacteriuminduced peroxidase $P O X 8.1$ and $P O X 22.3$ that show higher expression in resistant rice cultivars than susceptible ones following inoculation with $X$. oryzae pv. oryzae (Chittoor et al. 1997). However, the transient expression of B. graminis $\mathrm{f}$. sp. hordei-inducible barley peroxidase gene $\operatorname{Pr} x 7$, but not $\operatorname{Pr} x 8$, results in increased susceptibility of barley epidermal cells to the powdery mildew (Kristensen et al. 2001). It is worthy to note that $\operatorname{Pr} x 7$ shares $80 \%$ amino acid identity to TmPRX9 (Table 1) and that barley $\operatorname{Prx} 8$ shares $87 \%$ identity with TmPRX1, but whether or not they also are related to susceptibility or resistance is unknown. New findings also are challenging the traditional view of the role of CWAs in defense responses (Greenshields et al. 2004; Zeyen et al. 2002), and further study is required to investigate the biological function of each TmPRX.

RT-PCR analysis showed differential tissue-specific expression and localization patterns among the $10 \mathrm{TmPRX}$. Despite reported correlations between PRXs and CWAs (Scott-Craig et al. 1995), all six members from cluster 1 mainly were expressed in mesophyll cells after pathogen attack. Apart from

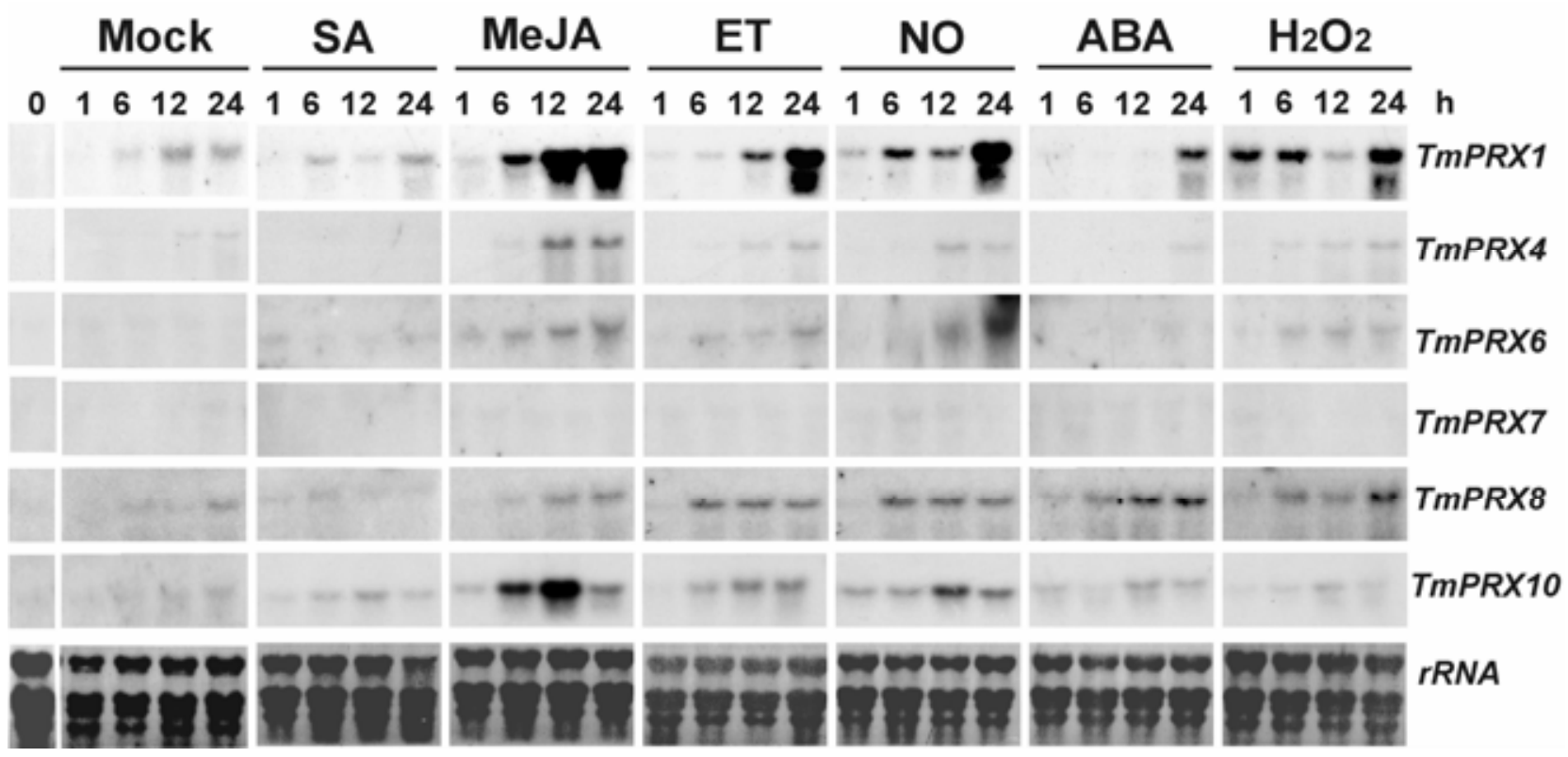

Fig. 5. RNA gel blot analysis of six TmPRX genes in response to signaling molecule treatment. Total RNA was isolated at 1 , 6 , 12 , and 24 h posttreatment from the 10-day-old primary leaves treated with salicylic acid (SA, $2 \mathrm{mM})$, ethephon $(100 \mu \mathrm{M})$, methyl jasmonate (MeJA, $200 \mu \mathrm{M})$, sodium nitroferricyanide (III) dihydrate (nitric oxide [NO], $10 \mathrm{mM}$ ), abscisic acid (ABA, $100 \mu \mathrm{M})$, and $\mathrm{H}_{2} \mathrm{O}_{2}(10 \mathrm{mM})$. Mock-treated leaves were used as controls. Transcript levels of $P R X$ genes were analyzed with ${ }^{32} \mathrm{P}$-labeled cDNA probes for TmPRX1, TmPRX4, TmPRX6, TmPRX7, TmPRX8, and TmPRX10. Total RNA was loaded at 20 $\mu \mathrm{g}$ per lane and equal loading was monitored by methylene blue staining of ribosomal RNA. 
TmPRX6 (the most divergent cluster 1 PRX), which showed relatively constant expression, the cluster 1 genes also were all induced following $B$. graminis f. sp. tritici attack. Members belonging to clusters 3 and 4 (i.e., with a CTE) also were induced following attack, but were expressed more strongly in the epidermis. The transcript accumulation of cluster $1 \mathrm{TmPRXs}$ in the mesophyll seems counterintuitive, given the exclusive interaction of $B$. graminis f. sp. tritici and the epidermis. How-

\section{A}
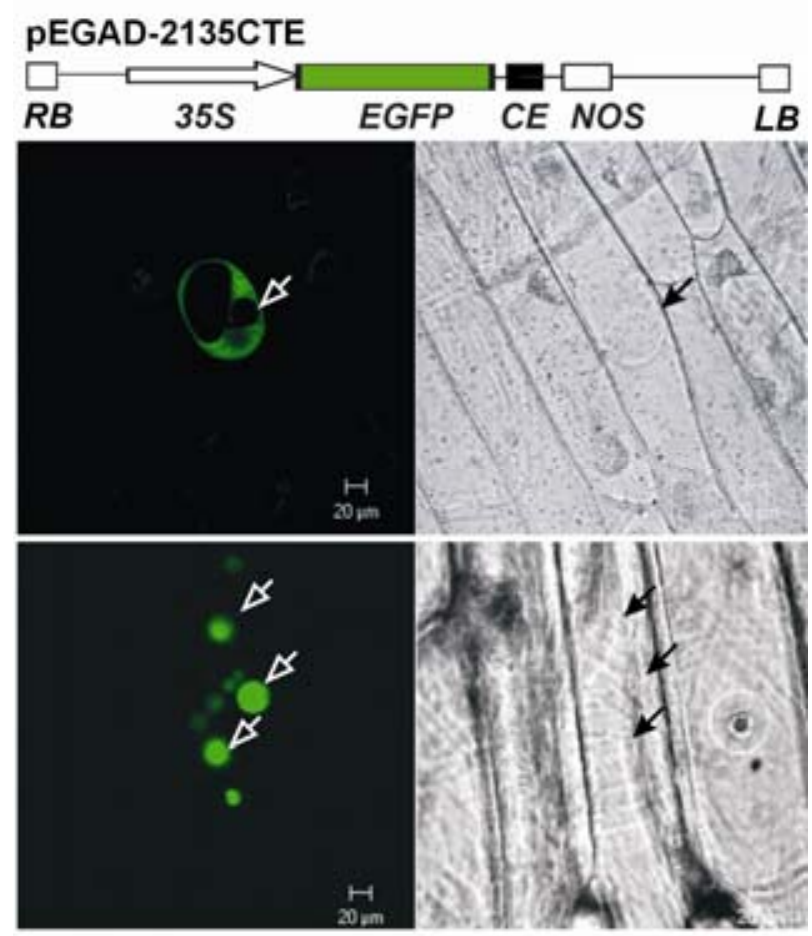

$\mathrm{B}$
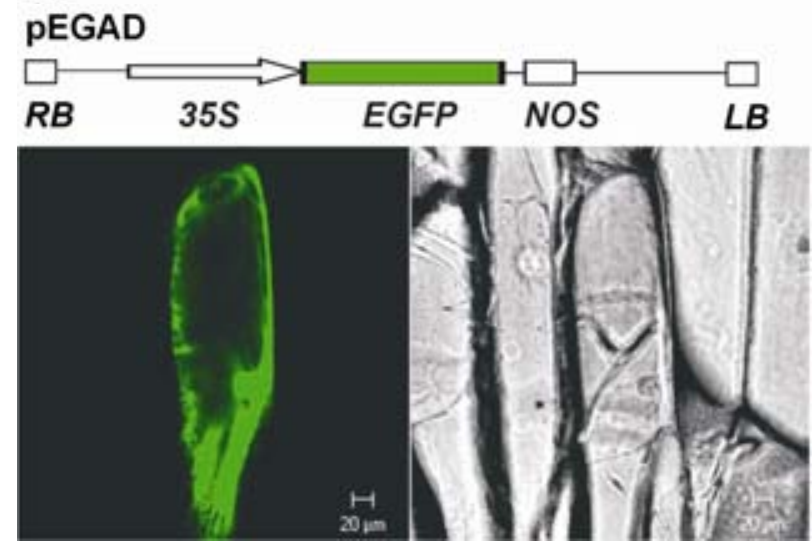

Fig. 6. Subcellular localization of green fluorescent protein-C-terminal extension (GFP-CTE) fusion protein. The constructs were introduced into onion epidermal cells by particle bombardment and the transformed onion epidermis was observed by confocal laser scanning microscopy (CSLM). The arrow heads indicate the location of vacuoles. Scale bar: $20 \mu \mathrm{m}$. A, Left columns depict the vacuolar localization of pEGAD-2135CTE under CSLM. The right columns depict the corresponding onion cells observed by phase microscopy. The construct showing that TmPRX8 C-terminal sequence (NPASSSSSAYAGVIEMLRRPGSDDKVAKG) was fused in frame to the $\mathrm{C}$ terminus of the enhanced GFP (EGFP), under the control of Cauliflower mosaic virus $35 \mathrm{~S}$ promoter and NOS terminator, is shown above. B, The left column depicts the cytosol and nucleus localization of GFP control observed by CLSM. The right column depicts the corresponding onion cells observed by phase microscopy. ever, Vanacker and associates (2000) noted that, during HR in Mla- 1 resistant barley, B. graminis f. sp. horde $i$ attack elicited $\mathrm{H}_{2} \mathrm{O}_{2}$ accumulation in the mesophyll before it began to accumulate in the epidermis. Unfortunately, differences between the resistant HR of Mla- 1 barley and the susceptible reaction in line 441, where epidermal CWA-associated $\mathrm{H}_{2} \mathrm{O}_{2}$ began to accumulate as early as $6 \mathrm{hpi}$, make it difficult to draw convincing parallels between the two systems. Previous reports also have found mesophyll- or epidermis-specific defense gene induction in barley after pathogen attack (Gregersen et al. 1997; Steiner-Lange et al. 2003; Wei et al. 1998). Regardless of the mesophyll-associated role of the cluster 1 TmPRXs, it is important to note that most members of the cluster were induced in the epidermis as well, especially at $24 \mathrm{hpi}$, and that the previously reported role of these peroxidases in CWA formation (Scott-Craig et al. 1995) cannot be discounted.

In addition to pathogen infection, salinity, drought, low temperature, and mechanical damage have been reported to induce gene expression in specific or cross-talk patterns (Knight and Knight 2001; Pastori and Foyer 2002). We found that $\mathrm{NaCl}$ was the most efficient inducer of TmPRX gene expression. Remarkably, $\mathrm{NaCl}$ was the only inducer for the TmPRX7 gene expression among all of the stressors we tested (Figs. 2, 3, 4, and 5). The significant induction of TmPRXs by salt implies cross-talk between responses to pathogen attack and reactions to high salt.

The high induction of TmPRXs by MeJA rather than by SA indicated that it is likely MeJA, rather than SA, playing an important role as $P R$ signal in monocot wheat. Our result is consistent with that of another monocot plant, rice, in which a number of $P R$ gene products at mRNA and protein levels were induced by exogenous application of MeJA rather than SA (Schweizer et al. 1997; Yang et al. 2004). In barley, $\mathrm{H}_{2} \mathrm{O}_{2}$ instead of SA accumulation was found after powdery mildew fungus infection (Hückelhoven et al. 1999). Except for MeJA, $T m P R X$ genes also showed the responses to other stress-signal-

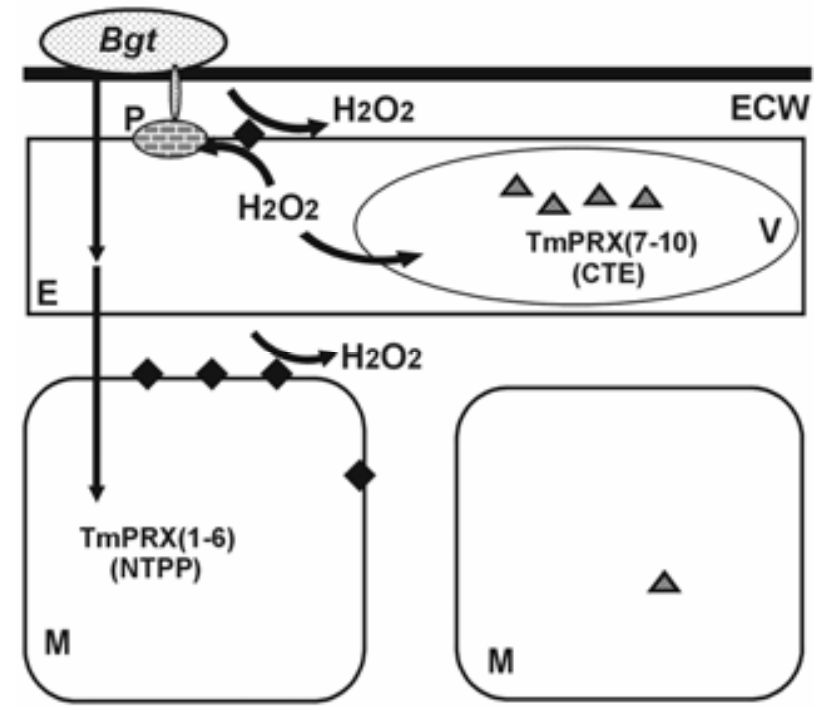

Fig. 7. Working model interpreting the relationship between the localization of sequence-dependent TmPRXs and $\mathrm{H}_{2} \mathrm{O}_{2}$ generation and scavenging. Following pathogen attack, the six cluster 1 NTPP-type TmPRX1-6 (diamonds) likely are associated with $\mathrm{H}_{2} \mathrm{O}_{2}$ generation and likely are located primarily in the mesophyll (M) cell wall, but also are found in the epidermal (E) cell wall (ECW). The C-terminal extension (CTE)-type TmPRX7-9 (triangles) mainly are found in epidermal vacuoles (V) where they probably detoxify $\mathrm{H}_{2} \mathrm{O}_{2}$. Straight arrows represent the pathogen-associated molecular patterns perceived by the plant. Curved arrows represent the generation and scavenging of $\mathrm{H}_{2} \mathrm{O}_{2}$ by TmPRXs. Bgt: conidium of Blumeria graminis f. sp. tritici; P: papilla. 
ing molecules such as ethylene and nitric oxide, to some extent. The differential expression patterns in response to various stress signals may reflect the fine-tuning regulation of each gene through different pathways under varied stimuli so that plants can avoid inappropriate gene expression, consistent with evidence of significant cross-talk among the signaling pathways (Cheong et al. 2002; Feys and Parker 2000).

Typical peroxidases are synthesized as a proprotein with an NTPP and with or without a CTE, which are removed before or concomitant with production of the mature protein (Buffard et al. 1990; Johansson et al. 1992; Rasmussen et al. 1999). The major compartmentalization of PRXs has been hypothesized in either cell wall or vacuole, sorted probably by the NTPP and CTE, respectively, but direct experimental evidence has been lacking, especially for the function of CTE. Kristensen and associates (1999) found that barley Prx7 never was present in extracellular washing fluid despite an NTPP, and suggested that the protein was retained in the vacuole due to its CTE. Matsui and colleagues (2003) demonstrated that NTPP and CTE are combinational signals for vacuolar targeting of the horseradish HRPC, a broadly used reporter enzyme, in heterologous tobacco BY2 cells. However, they did not observe vacuolar localization determined by the 15-aa-long CTE (QGQIRLN CRVVNSNS) alone. Two types of vacuolar-sorting determinants (VSDs) have been identified (Neuhaus and Rogers 1998): the sequence-specific VSD (ssVSD) and the C-terminal VSD (ctVSD). Unlike the variable ctVSD, ssVSDs have a consensus motif N-P-I-R. No consensus ssVSD motif is present in the TmPRXs; therefore, we speculate that variable CTEs among the TmPRXs might be the sorting signals. The transient expression in onion cell with GFP fusion protein derived from CTE of one representative TmPRX8 gene confirms that the CTE peptide in this peroxidase is indeed the major sorting signal to vacuoles. This finding is critical for speculating on the behavior of this enzyme and other similar PRXs in terms of spatial compartmentalization of these multifunctional enzymes.

Accumulation of ROS is one of the early defense events in response to pathogen attack and to various environmental stresses. PRXs oxidize a broad range of substrates by reducing $\mathrm{H}_{2} \mathrm{O}_{2}$ into water, although the precise relationship between the peroxidase activity and $\mathrm{H}_{2} \mathrm{O}_{2}$ accumulation remains elusive. $\mathrm{H}_{2} \mathrm{O}_{2}$ is an electron-accepting substrate for PRX-dependent reactions; thus, PRXs generally are considered to be merely ROS-detoxifying enzymes. However, on certain occasions, the extracellularly secreted cell-wall-type PRXs actually produce $\mathrm{H}_{2} \mathrm{O}_{2}$ or other radicals (Blee et al. 2001; Bolwell et al. 2002; Bolwell and Wojtaszek 1997; Kawano 2003). Bolwell and associates (2002) proposed a three-component system for generation of the apoplastic oxidative burst based mostly on studies of the French bean peroxidase FBP1. The components of this system are the PRX, alkalinization of the apoplastic space, and the reductant. FBP1 provides the peroxidase activity for $\mathrm{H}_{2} \mathrm{O}_{2}$ production following alkalinization of the apoplast (Bolwell et al. 2002).

Among the $10 \mathrm{TmPRXs}$ in this study, two possible mechanisms relating to ROS might be hypothesized (Fig. 7). The six members from cluster 1 (TmPRX1 to TmPRX6) probably are associated with ROS production and probably are cell wall localized. TmPRX3 specifically could be a functional homolog of FBP1, given its induction pattern and pI. The produced $\mathrm{H}_{2} \mathrm{O}_{2}$ may function to reinforce the cell wall through polymerization reactions or by direct toxicity to the fungus. In Arabidopsis and tobacco, NADPH oxidases generally are considered responsible for the oxidative burst in response to pathogen attack (Mittler et al. 2004; Torres et al. 2002; Yoshioka et al. 2003). Thus, indirect support for the involvement of peroxidases in oxidative burst generation also is available through the insensitivity of barley and T. monococcum ROS accumulation to diphenylene iodonium (DPI), an NADPH oxidase inhibitor (Hückelhoven and Kogel 1998; Y. Wei, unpublished data). The other four TmPRXs (TmPRX7 to TmPRX10) probably are associated with ROS scavenging to alleviate oxidative damage and might be localized mainly in vacuoles. This model is supported by the induction patterns of the TmPRXs by Northern analysis following inoculation with $B$. graminis f. sp. tritici. For instance, although TmPRX1, TmPRX4, and TmPRX6 transcription remains throughout the infection time course in the susceptible wheat line 441 , after 48 hpi in the resistant line 453 , transcription is reduced to undetectable levels, signifying a successful defense reaction. Conversely, TmPRX8 and TmPRX10 transcription continues until the end of the time course in both the resistant and susceptible lines, suggesting that these $T m P R X$-encoded products are involved in returning the plants to a condition of normal redox homeostasis.

\section{MATERIALS AND METHODS}

\section{Plant and fungal material.}

Over 150 accession lines of the diploid wheat (T. monococcum L.; AA genome) were screened for susceptibility to a powdery mildew (B. graminis f. sp. tritici) isolate which originally was isolated from field $\mathrm{cv}$. Conway ( $T$. aestivum, AABBDD genome) in Saskatoon, Canada. The fungus was maintained on cv. Conway for the source of fresh conidia. One susceptible $T$. monococcum line (441, accession number TG13182) was inoculated with $B$. graminis f. sp. tritici. A CWA-based resistant line (453, accession number TG13192), which completely inhibits fungal growth at the penetration stage, was used for time course assay of pathogen attack. Plants were grown in a growth chamber with a cycle of $16 \mathrm{~h}$ of light and $8 \mathrm{~h}$ of dark at $20^{\circ} \mathrm{C}$ with light intensity of 100 to 200 $\mu \mathrm{E} \mathrm{m} \mathrm{m}^{-2} \mathrm{~s}^{-1}$. The primary leaves of 10 -day-old wheat plants were inoculated with $B$. graminis $\mathrm{f}$. sp. tritici by tapping the conidia from heavily infected plants onto abaxial side of the leaves.

\section{Establishment of wheat epidermis cDNA library.}

Abaxial epidermis from infected primary leaves was carefully stripped off at 24 and $48 \mathrm{hpi}$. The inoculum density was approximately 100 conidia $\mathrm{mm}^{-2}$, calculated to challenge each host cell with at least one spore (Wei et al. 1998). Some residual mesophyll contamination of the epidermal tissues was inevitable, especially at $48 \mathrm{hpi}$, but we estimate a maximum of $5 \%$ contamination overall, and this has not greatly impaired the specificity of the library. Epidermal strips were flash frozen in liquid nitrogen and then stored at $-80^{\circ} \mathrm{C}$ until further use. Total RNA was extracted according to Wilkins and Smart's method (1996). Poly(A) ${ }^{+}$RNA was isolated by the PolyATract mRNA Isolation System according to the manufacturer's instruction (Promega Corp., Madison, WI, U.S.A.). cDNA was synthesized and cloned into vector ZAPII (Stratagene, La Jolla, CA, U.S.A.) according to the manufacturer's recommendations. Mass conversion of the phage library to the plasmid library and plasmid DNA preparation were performed by standard protocols (Sambrook and Russell 2001).

\section{Annotation of wheat PRXs and data analysis.}

It appears necessary to rationalize the nomenclature of the $T m P R X s$ we isolated, because different names have been given to homologous genes, thereby impeding the comparison between published data. For example, " $P O X$ ", " $P R X$ ", and "POD" have been used for peroxidase, and peroxiredoxins also use " $P R X$ " as a symbol in the literature. Herein, we adopt the nomenclatures used in Arabidopsis (Valério et al. 2004) 
and rice (Passardi et al. 2004), with the letters " $T m$ " for $T$. monococcum and "PRX" for peroxidase, followed by a number. All the candidate peroxidase ESTs were double-sequenced to confirm accuracy and BLAST searches were performed via the National Center for Biotechnology Information web server. The alignment was performed via ClustalW web service of the Pasteur Institute. The phylogenetic tree was constructed using PROTDIST and NEIGHBOR methods from the PHYLIP 3.6 phylogeny package (J. Felsenstein, University of Washington).

Biotic stress, abiotic stress, and signal molecule treatments.

Ten-day-old diploid susceptible wheat seedlings (line 441) were used for all the treatments, except for the time course of pathogen infection, in which a resistant line (453) was used as well. For pathogen challenge, plants were inoculated with a high density of $B$. graminis f. sp. tritici conidia (approximately 100 conidia $\mathrm{mm}^{-2}$ ) as described previously. The inoculated leaves were collected at 0 to 144 hpi for RNA isolation. Four abiotic stress treatments (salt, cold, dehydration, and wounding) also were performed. Perlite-grown seedlings were floated in water containing $200 \mathrm{mM} \mathrm{NaCl}$ for salt stress or transferred to paper towels for dehydration. For cold treatment, plants were placed at $4^{\circ} \mathrm{C}$. For wounding stress, fine powdered silicon carbide was rubbed gently on the abaxial side of leaves until slightly damaged. Treated tissues were collected at 1, 6, 12, and $24 \mathrm{~h}$ after treatment. For signal compound treatment, plants were sprayed with solutions containing $2 \mathrm{mM} \mathrm{SA}, 200$ $\mu \mathrm{M}$ MeJA, $100 \mu \mathrm{M}$ ethephon (ET-releasing agent), $10 \mathrm{mM}$ sodium nitroferricyanide (III) dihydrate (NO-releasing agent), $100 \mu \mathrm{M} \mathrm{ABA}$, and $10 \mathrm{mM} \mathrm{H}_{2} \mathrm{O}_{2}$, respectively. Triton $\mathrm{X}-100$ $(0.125 \%)$ was added to each solution. The leaves were harvested at $1,6,12$, and $24 \mathrm{~h}$ after treatment. Water- or solvent-mocked plants served as controls. All collected samples were frozen immediately in liquid nitrogen and stored at $-80^{\circ} \mathrm{C}$ until assayed.

\section{RNA gel blot analysis.}

Total RNA was isolated by phenol/chloroform extraction and $\mathrm{LiCl}$ precipitation (Wilkins and Smart 1996). Samples (20 $\mu \mathrm{g})$ were separated on a $1.2 \%$ denaturing agarose gel, stained with $0.02 \%$ methylene blue, photographed to allow for comparison of RNA loading, transferred onto a GeneScreen Plus Hybridization Transfer Membrane (NEN Life Sciences Products, Inc., Boston), UV cross-linked or baked at $80^{\circ} \mathrm{C}$, and hybridized at $65^{\circ} \mathrm{C}$ in QuickHyb solution (Stratagene) with $\left[{ }^{32} \mathrm{P}\right] \mathrm{dCTP}$ radiolabeled probes consisting of the entire coding region of the TmPRXs. Following hybridization, membranes were washed twice at room temperature in $2 \times \mathrm{SSC}(1 \times \mathrm{SSC}$ is $0.15 \mathrm{M} \mathrm{NaCl}$ plus $0.015 \mathrm{M}$ sodium citrate), $0.1 \%$ sodium dodecyl sulfate (SDS) for $15 \mathrm{~min}$ and once in $0.1 \times \mathrm{SSC}, 0.1 \%$ $\mathrm{SDS}$ at $65^{\circ} \mathrm{C}$ for $30 \mathrm{~min}$, then exposed on X-ray film (Sterlin Diagnostics, Newark, DE, U.S.A.). When needed, membranes were stripped in boiling $0.1 \times$ SSC, $0.1 \%$ SDS solution for 30 min before rehybridization. All hybridizations repeated at least at twice.

\section{RT-PCR.}

Total RNA was isolated from the $B$. graminis f. sp. Triticiinfected epidermal and mesophyll cells. cDNA synthesis were performed using SuperScript reverse transcriptase (Invitrogen Life Technologies, Burlington, ON, Canada) according to the manufacturer's instructions. Ten pairs of specific primers for peroxidase genes were generated based on areas of low sequence homology, among which most primers were located at $5^{\prime}$ or $3^{\prime}$ untranslated regions (Table 2 ). To ensure that equal amounts of mRNA were used, a positive control encoding TmGPD1 gene was normalized using primers GPDH1F and
GPDH1R (Table 2). PCR amplifications were performed using Taq polymerase (Amersham Pharmacia Biotech, Piscataway, NJ, U.S.A.) under the following conditions: $94^{\circ} \mathrm{C}$ for $20 \mathrm{~s}, 55$ to $62^{\circ} \mathrm{C}$ for $20 \mathrm{~s}$, and $72^{\circ} \mathrm{C}$ for $60 \mathrm{~s}$ for 25 cycles in a thermal Eppendorf Mastercycler (Hamburg, Germany).

\section{GFP fluorescence and transient expression.}

A putative C-terminal extension fragment of TmPRX8 was amplified from plasmid and subcloned into TA vector using primers flanking restriction site EcoRI or BamH1: 2135F3 5'GAATTCAACCCGGCCTCCTCTTCTTCGTCCGCC and 2135R1 5'-GGATCCTCAGCCCTTGGCGACCTTATCGTC. After verifying by sequencing, the fragment was cleaved and inserted in frame into the EcoRI/BamHI site of plant expression vector pEGAD (Cutler et al. 2000) to create an N-terminal fusion to the enhanced green fluorescence protein $(E G F P)$ gene under the control of the CaMV35S promoter (35S::GFP2135CTE). Transient expression of 35S::GFP-2135CTE in white onion (Allium cepa) epidermal cells was performed using a PDS-1000/He biolistic particle delivery system (BioRad, Mississauga, Ontario, Canada) with 1- $\mu$ m gold particles. Column-purified (Qiagen, Hilden, Germany) plasmid DNA was coated onto particles according to the manufacturer's instructions. After bombardment, plates were placed in the dark at $22^{\circ} \mathrm{C}$ and observed 15 to $20 \mathrm{~h}$ after bombardment with a confocal laser scanning microscope LSM510 (Zeiss, Oberkochen, Germany) using the condition of excitation/emission wavelength $=488 \mathrm{~nm} / 510$ to $530 \mathrm{~nm}$ or a Leica FluoIII microscope (Wetzlar, Germany) using GFP filters.

\section{ACKNOWLEDGMENTS}

We thank R. Hirji and X. Wu for technical support, S. Fox for providing the wheat accessions, and the DNA Technology Group at the National Research Council of Canada-Plant Biotechnology Institute for oligonucleotide synthesis and sequencing. This work was supported by grants from the National Science and Engineering Research Council of Canada and the Canada Foundation for Innovation to Y. Wei, from the Genomics and Health Initiative of NRC to G. Selvaraj, and by a Canadian Wheat Board Fellowship to D. L. Greenshields.

\section{LITERATURE CITED}

Amaya, I., Botella, M. A., de la Calle, M., Medina, M. I., Heredia, A., Bressan, R. A., Hasegawa, P. M., Quesada, M. A., and Valpuesta, V. 1999. Improved germination under osmotic stress of tobacco plants overexpressing a cell wall peroxidase. FEBS (Fed. Euro. Biol. Soc.) Lett. 457:80-84.

Baga, M., Chibbar, R. N., and Kartha, K. K. 1995. Molecular cloning and expression analysis of peroxidase genes from wheat. Plant Mol. Biol. 29:647-662.

Blee, K. A., Jupe, S. C., Richard, G., Zimmerlin, A., Davies, D. R., and Bolwell, G. P. 2001. Molecular identification and expression of the peroxidase responsible for the oxidative burst in French bean (Phaseolus vulgaris $L$.) and related members of the gene family. Plant Mol Biol. 47:607-620.

Bolwell, G. P., Bindschedler, L. V., Blee, K. A., Butt, V. S., Davies, D. R., Gardner, S. L., Gerrish, C., and Minibayeva, F. 2002. The apoplastic oxidative burst in response to biotic stress in plants: a three-component system. J. Exp. Bot. 53:1367-1376.

Bolwell, G. P., and Wojtaszek, P. 1997. Mechanisms for the generation of reactive oxygen species in plant defence, a broad perspective. Physiol. Mol. Plant Pathol. 51:347-366.

Buffard, D., Breda, C., van Huystee, R. B., Asemota, O., Pierre, M., Ha, D. B. D., and Esnault, R. 1990. Molecular cloning of complementary DNAs encoding two cationic peroxidases from cultivated peanut cells. Proc. Natl. Acad. Sci. U.S.A. 87:8874-8878.

Cheong, Y. H., Chang, H. S., Gupta, R., Wang, X., Zhu, T., and Luan, S. 2002. Transcriptional profiling reveals novel interactions between wounding, pathogen, abiotic stress, and hormonal responses in Arabidopsis. Plant Physiol. 129:661-677.

Chini, A., Grant, J. J., Seki, M., Shinozaki, K., and Loake, G. J. 2004. Drought tolerance established by enhanced expression of the CC-NBS- 
LRR gene, ADR1, requires salicylic acid, EDS1 and ABI1. Plant J. 38:810-822.

Chittoor, J. M., Leach, J. E., and White, F. F. 1997. Differential induction of a peroxidase gene family during infection of rice by Xanthomonas oryzae pv. oryzae. Mol. Plant-Microbe Interact. 10:861-871.

Chittoor, J. M., Leach, J. E., and White, F. F. 1999. Induction of peroxidase during defense against pathogens. Page 171-193 in: PathogenesisRelated Proteins in Plants. S. K. Datta and S. Muthukrishnan, eds. CRC Press. Boca Raton, FL, U.S.A.

Curtis, M. D., Rae, A. L., Rusu, A. G., Harrison, S. J., and Manners, J. M 1997. A peroxidase gene promoter induced by phytopathogens and methyl jasmonate in transgenic plants. Mol. Plant-Microbe. Interact. 10:326-338.

Cutler, S. R., Ehrhardt, D. W., Griffitts, J. S., and Somerville, C. R. 2000 Random GFP::cDNA fusions enable visualization of subcellular structures in cells of Arabidopsis at a high frequency. Proc. Natl. Acad. Sci. U.S.A. 97:3718-3723.

Delannoy, E., Jalloul, A., Assigbetse, K., Marmey, P., Geiger, J. P., Lherminier, J., Daniel, J. F., Martinez, C., and Nicole, M. 2003. Activity of class-III peroxidases in the defense of cotton to bacterial blight. Mol. Plant-Microbe Interact. 16:1030-1038

Desikan, R., Mackerness, S. A. H., Hancock, J. T., and Neill, S. J. 2001. Regulation of the Arabidopsis transcriptosome by oxidative stress. Plant Physiol. 127:159-172.

Dong, X. 2001. Genetic dissection of systemic acquired resistance. Curr. Opin. Plant Biol. 4:309-314.

Duroux, L., and Welinder, K. G. 2003. The peroxidase gene family in plants: a phylogenetic overview. J. Mol. Evol. 57:397-407.

Espelie, K. E., Franceschi, V. R., and Kolattukudy, P. E. 1986. Immunocytochemical localization and time course of appearance of an anionic peroxidase associated with suberization in wound-healing potato tuber tissue. Plant Physiol. 81:487-492.

Feys, B. J., and Parker, J. E. 2000. Interplay of signaling pathways in plant disease resistance. Trends Genet. 16:449-455.

Fry, S. C. 1986. Cross-linking of matrix polymers in the growing cell walls of angiosperms. Annu. Rev. Plant Physiol. 37:165-186.

Fujita, K., Suzuki, T., Kunoh, H., Carver, T. L. W., Thomas, B. J., Gurr, S. and Shiraishi, T. 2004. Induced inaccessibility in barley cells exposed to extracellular material released by non-pathogenic powdery mildew conidia. Physiol. Mol. Plant Pathol. DOI: 10.1016/j.pmpp.2004.08.006. Online publication

Gajhede, M., Schuller, D. J., Henriksen, A., Smith, A. T., and Poulos, T. L. 1997. Crystal structure of horseradish peroxidase $\mathrm{C}$ at $215 \AA$ resolution. Nat. Struct. Biol. 4:1032-1038.

Greenshields, D. L., Liu, G., Selvaraj, G., and Wei, Y. 2004. New insights into ancient resistance: the molecular side of cell wall appositions. Phytoprotection 85:49-52.

Gregersen, P. L., Thordal-Christensen, H., Förster, H., and Collinge, D. B 1997. Differential gene transcript accumulation in barley leaf epidermis and mesophyll in response to attack by Blumeria graminis f. sp. hordei (syn. Erysiphe graminis f. sp. hordei). Physiol. Mol. Plant Pathol. 51:85-97.

Hammond-Kosack, K. E., and Parker, J. E. 2003. Deciphering plant-pathogen communication: fresh perspectives for molecular resistance breeding. Curr. Opin. Biotechnol. 14:177-193.

Hiraga, S., Sasaki, K., Ito, H., Ohashi, Y., and Matsui, H. 2001. A large family of class-III plant peroxidases. Plant Cell Physiol. 42:462-468.

Hiraga, S., Yamamoto, K., Ito, H., Sasaki, K., Matsui, H., Honma, M. Nagamura, Y., Sasaki, T., and Ohashi, Y. 2000. Diverse expression profiles of 21 rice peroxidase genes. FEBS (Fed. Eur. Biol. Soc.) Lett. 471:245-250.

Hückelhoven, R., and Kogel, K.-H. 1998. Tissue-specific superoxide generation at interaction sites in resistant and susceptible near-isogenic barley lines attacked by the powdery mildew fungus (Erysiphe graminis $\mathrm{f}$. sp. hordei). Mol. Plant-Microbe Interact. 11:292-300.

Hückelhoven, R., Fodor, J., Preis, C., and Kogel, K. 1999. Hypersensitive cell death and papilla formation in barley attacked by the powdery mildew fungus are associated with hydrogen peroxide but not with salicylic acid accumulation. Plant Physiol. 119:1251-1260.

Ito, H., Kimizuka, F., Ohbayashi, A., Matsui, H., Honma, M., Shinmyo, A., Ohashi, Y., and Rodrigues, R. L. 1994. Molecular cloning and characterization of two complementary cDNAs encoding putative peroxidase from rice (Oryza sativa L.). Plant Cell Rep. 13:361-366.

Johansson, A., Rasmussen, S. K., Harthill, J. E., and Welinder, K. G. 1992. cDNA, amino acid and carbohydrate sequence of barley seed-specific peroxidase BP1. Plant Mol. Biol. 18:1151-1161.

Kawano, T. 2003. Roles of the reactive oxygen species-generating peroxidase reactions in plant defense and growth induction. Plant Cell Rep. 21:829-837.
Knight, H., and Knight, M. R. 2001. Abiotic stress signaling pathways: specificity and cross-talk. Trends Plant Sci. 6:262-267.

Kristensen, B. K., Ammitzböll, H., Rasmussen, S. K., and Nielsen, K. A 2001. Transient expression of a vacuolar peroxidase increases susceptibility of epidermal barley cells to powdery mildew. Mol. Plant Pathol. 2:311-317.

Kristensen, B. K., Bloch, H., and Rasmussen, S. K. 1999. Barley coleoptile peroxidases. Purification molecular cloning and induction by pathogens. Plant Physiol. 120:501-512.

Lagrimini, L. M., Joly, R. J., Dunlap, J. R., and Liu, T. T. Y. 1997. The consequence of peroxidase overexpression in transgenic plants on root growth and development. Plant Mol. Biol. 33:887-895.

Llorente, F., Lopez-Cobollo, R. M., Catala, R., Martinez-Zapater, J. M. and Salinas, J. 2002. A novel cold-inducible gene from Arabidopsis, $\mathrm{RCI} 3$, encodes a peroxidase that constitutes a component for stress tolerance. Plant J. 32:13-24.

Longu, S., Medda, R., Padiglia, A., Pedersen, J. Z., and Floris, G. 2004. The reaction mechanism of plant peroxidases. Ital. J. Biochem. 53:41-45.

Matsui, T., Nakayama, H., Yoshida, K., and Shinmyo, A. 2003. Vesicular transport route of horseradish $\mathrm{Cla}$ peroxidase is regulated by $\mathrm{N}$ - and $\mathrm{C}$ terminal propeptides in tobacco cells. Appl. Microbiol. Biotechnol. 62:517-522.

Mittler, R., Vanderauwera, S., Gollery, M., and Van Breusegem, F. 2004 Reactive oxygen gene network of plants. Trends Plant Sci. 9:490-498.

Neill, S. J., Desikan, R., Clarke, A., Hurst, R. D., and Hancock, J. T. 2002. Hydrogen peroxide and nitric oxide as signaling molecules in plants. J. Exp. Bot. 53:1237-1247.

Neuhaus, J. M., and Rogers, J. C. 1998. Sorting of proteins to vacuole in plant cells. Plant Mol. Biol. 38:127-144.

Park, S. Y., Ryu, S. H., Kwon, S. Y., Lee, H. S., Kim, J. G., and Kwak, S. S. 2003. Differential expression of six novel peroxidase cDNAs from cell cultures of sweet potato in response to stress. Mol. Genet. Genomics 269:542-552.

Passardi, F., Longet, D., Penel, C., and Dunand, C. 2004. The class-III peroxidase multigenic family in rice and its evolution in land plants. Phytochemistry 65:1879-1893.

Pastori, G. M., and Foyer, C. H. 2002. Common components, networks, and pathways of cross-tolerance to stress. The central role of "redox" and abscisic acid-mediated controls. Plant Physiol. 129:460-468

Rasmussen, J. B., Smith, J. A., William, S., Burkhart, W., Ward, E. Somerville, S. G., Ryals, J., and Hammerschmidt, R. 1995. cDNA cloning and systemic expression of acidic peroxidases associated with systemic acquired resistance to disease in cucumber. Physiol. Mol. Plant Pathol. 46:389-400.

Rebmann, G., Hertig, C., Bull, J., Mauch, F., and Dudler, R. 1991. Cloning and sequencing of cDNAs encoding a pathogen-induced putative peroxidase of wheat (Triticum aestivum L.). Plant Mol. Biol. 16:329-331.

Roberts, E., and Kolattukudy, P. E. 1989. Molecular cloning nucleotide sequence and abscisic acid induction of a suberization-associated highly anionic peroxidase. Mol. Gen. Genet. 217:223-232.

Sambrook, J., and Russell, D. W. 2001. Molecular Cloning: A Laboratory Manual. Cold Spring Harbor Laboratory Press, Cold Spring Harbor, NY, U.S.A.

Schweizer, P., Buchala, A., Silverman, P., Seskar, M., Raskin, I., and Metraux, J. P. 1997. Jasmonate-inducible genes are activated in rice by pathogen attack without a concomitant increase in endogenous jasmonic acid levels. Plant Physiol. 114:79-88.

Scott-Craig, J. S., Kerby, K. B., Stein, B. D., and Somerville, S. C. 1995. Expression of an extracellular peroxidase that is induced in barely (Hordeum vulgare) by the powdery mildew pathogen (Erysiphe graminis f. sp. hordei). Physiol. Mol. Plant Pathol. 47:407-418.

Steiner-Lange, S., Fischer, A., Boettcher, A., Rouhara, I., Liedgens, H. Schmelzer, E., and Knogge, W. 2003. Differential defense reactions in leaf tissues of barley in response to infection by Rhynchosporium secalis and to treatment with a fungal avirulence gene product. Mol. Plant-Microbe Interact. 16:893-902.

Tognolli, M., Penel, C., Greppin, H., and Simon, P. 2002. Analysis and expression of the class-III peroxidase large gene family in Arabidopsis thaliana. Gene 288:129-138.

Torres, M. A., Dangl, J. L., and Jones, J. D. G. 2002. Arabidopsis gp91 ${ }^{\text {phox }}$ homologues AtrbohD and AtrbohF are required for accumulation of reactive oxygen intermediates in the plant defense response. Proc. Natl. Acad. Sci. U.S.A. 99:517-522.

Valério, L., De Meyer, M., Penel, C., and Dunand, C. 2004. Expression analysis of the Arabidopsis peroxidase multigenic family. Phytochemistry 65:1331-1342.

Vanacker, H., Carver, T. L. W., and Foyer, C. H. 2000. Early $\mathrm{H}_{2} \mathrm{O}_{2}$ accumulation in mesophyll cells leads to induction of glutathione during the hypersensitive response in the barley-powdery mildew interaction. Plant 
Physiol. 123:1289-1300.

van Loon, L. C., and van Strien, E. A. 1999. The families of pathogenesisrelated proteins, their activities, and comparative analysis of PR-1 type proteins. Physiol. Mol. Plant Pathol. 55:85-97.

Vitale, A., and Raikhel, N. V. 1999. What do proteins need to reach different vacuoles? Trends Plant Sci. 4:149-155.

Wei, Y., Zhang, Z., Andersen, C. H., Schmelzer, E., Gregersen, P. L., Collinge, D. B., Smedegaard-Petersen, V., and Thordal-Christensen, H. 1998. An epidermis/papilla-specific oxalate oxidase-like protein in the defence response of barley attacked by the powdery mildew fungus. Plant Mol. Biol. 36:101-112.

Welinder, K. G. 1992. Superfamily of plant, fungal and bacterial peroxidases. Curr. Opin. Struct. Biol. 2:388-393.

Welinder, K. G., Justesen, A. F., Kjaersgard, I. V., Jensen, R. B., Rasmussen, S. K., Jespersen, H. M., and Duroux, L. 2002. Structural diversity and transcription of class-III peroxidases from Arabidopsis thaliana. Eur. J. Biochem. 269:6063-6081.

Whetten, R. W., Mackay, J. J., and Sederoff, R. R. 1998. Recent advances in understanding lignin biosynthesis. Annu. Rev. Plant Physiol. Plant Mol. Biol. 49:585-609.

Wilkins, T., and Smart, L. B. 1996. Isolation of RNA from plant tissue. In:
A Laboratory Guide to RNA Isolation, Analysis, and Synthesis. P. A. Kreig, ed. J. Wiley and Sons, New York.

Wojtaszek, P. 1997. Oxidative burst: an early plant response to pathogen infection. Biochem. J. 322:681-692.

Yang, Y., Qi, M., and Mei, C. 2004. Endogenous salicylic acid protects rice plants from oxidative damage caused by aging as well as biotic and abiotic stress. Plant J. 40:909-919.

Yoshioka, H., Numata, N., Nakajima, K., Katou, S., Kawakita, K., Rowland, O., Jones, J. D., and Doke, N. 2003. Nicotiana benthamiana gp91phox homologs $N b r b o h A$ and $N b r b o h B$ participate in $\mathrm{H}_{2} \mathrm{O}_{2}$ accumulation and resistance to Phytophthora infestans. Plant Cell. 15:706-718.

Zeyen, R. J., Carver, T. L. W., and Lyngkjær, M. F. 2002. Epidermal cell papillae. Pages 107-125 in: The Powdery Mildews. A Comprehensive Treatise. R. R. Bélanger, W. R. Bushnell, A. J. Dik, and T. L. W. Carver, eds. American Phytopathological Society Press, St. Paul, MN, U.S.A.

\section{AUTHOR-RECOMMENDED INTERNET RESOURCE}

National Center for Biotechnology Information web server: www.ncbi.nlm.nih.gov 